\title{
Prevalence of modern contraceptive utilization and associated factors among women of reproductive age from 36-49 years in Ethiopia, 2018: Community based cross-sectional survey
}

Dereje Zena ( $\nabla$ derejezena@gmail.com )

https://orcid.org/0000-0002-4418-8899

Anemaw Asrat

Bahir Dar University

Agumas Fentahun

Family Guidance Association of Ethiopia

\section{Research note}

Keywords: modern Contraceptives use, Associated Factors and Women

Posted Date: August 13th, 2019

DOl: https://doi.org/10.21203/rs.2.12646/v1

License: (c) (i) This work is licensed under a Creative Commons Attribution 4.0 International License.

Read Full License 


\section{Abstract}

IIntroduction: Modern Contraceptive use allows people to attain their desired number of children and determine the spacing of pregnancies. Objective: The main objective of this study is to assess the Prevalence of modern contraceptive utilization and associated factors among women of reproductive age from 36-49 years in Ethiopia. Methodology: A community based, cross-sectional study was employed from January 1 to June 30, 2016, among women of reproductive age from 36-49 years in all regions of Ethiopia. A bivariate, multivariable logistic regression model was fit and statistical significance was determined with odds ratios and $95 \%$ confidence level. Result: The overall modern contraceptive prevalence rate was found to be $17 \%$. Being wealthy (Adjusted Odds Ratio $=4.12095 \% \mathrm{Cl}(2.853,5.949)$, higher educated (Adjusted Odds Ratio $=3.329,95 \% \mathrm{Cl}(2.065,5.368)$ and having more numbers of living children (Adjusted Odds Ratio $=1.714,95 \%(1.328,2.212)$ was significantly associated with use of modern contraceptive methods. Conclusion: The utilization of modern contraceptive method was low. Contraceptive utilization was associated with some socio-economic and socio-demographic factors like age, educational status, women wealth index and number of children. Keywords: modern Contraceptives use, Associated Factors and Women

\section{Introduction}

The history of family planning in Ethiopia started in the 1960s. So far Ethiopia faced many challenges to provide better access to family planning services for several decades (1).

Number of births and high-risk pregnancies are reduced through provision of safe and effective modern contraceptives like pills, female and male sterilization, IUD, inject-able, implants, male and female condom, diaphragm, and emergency contraception.

Modern contraceptive use enables people to make informed choices about their sexual and reproductive health rights. It creates an opportunity for women to pursue additional education and participate in public life, including paid employment in any organizations. Therefore, having smaller families allow parents to invest more in each child.

Ability of a woman to start a successful, continuous and appropriate contraceptive method is influenced by age, level of education, family wealth, number of children, their residence (urban/rural), Knowledge, attitude, frequency of listening mass Medias (radio) and access to the health care (2).

Delay and spacing childbearing are crucial to women's social and economic advancement. Women's ability to obtain and effectively use contraceptives has a positive impact on their education and workforce participation, as well as on subsequent outcomes related to income, family stability, mental health and children's well-being (3).

The aim of this study is to assess the Prevalence of modern contraceptive utilization and associated factors among women of reproductive age from 36-49 years in Ethiopia. 
Therefore, this assessment addresses the identified gaps by answering the following assessment questions:

- What are the key factors that affect use of modern contraceptive methods in Ethiopia?

- To what extent Modern contraceptives were utilized women of 36-49years of age in Ethiopia?

\section{Methods}

\section{- Study Setting}

The 2016 Ethiopia Demographic and Health Survey (2016 EDHS) was implemented by the Central Statistical Agency (CSA) from January 18, 2016, to June 27, 2016.to provide up-to-date estimates of key demographic and health indicators in all regions of Ethiopia. Ethiopia has a total population of about $105,350,020$ with annual growth rate of $2.8 \%$ (22). Currently, the country has a federal system of governance with nine regional states and two chartered cities, Addis Ababa (capital city of Ethiopia) and Dire Dawa. The rising age of marriage and the increasing proportion of women remaining single have contributed to fertility reduction. All the participants of the study were women, ranging from 36 to 49 years in age, and they have lived in the study area for at least 6 months. Women who were critically ill, could not provide informed consent or pregnant women were excluded from the study.

- $\quad$ Data Source

This study was conducted using a data obtained from the 2016 EDHS. This cross-sectional survey was administered at the household level throughout the country. The survey was conducted under the guidance of the Ministry of Health (MOH) and was implemented by the Central Statistical Agency (CSA).

The overall aim of using 2016 EDHS dataset was to assess the prevalence and its determinants of modern contraceptive utilization like: Age, proportion of Contraceptive use, number of children, wealth index, and relevance of media listening, residence and their occupation based on representative samples (3260).

- $\quad$ Sample Size Determination

Single population proportion formula with the assumption of $95 \%$ confidence interval, a margin of error of $5 \%$ was used to determine the sample size of this study by taking $25 \%$ of modern contraceptive use in Ethiopia as prevalence (18). For this study $10 \%$ of non-response rate was considered. Finally, a total sample size of 3260 was obtained.

- $\quad$ Data collection procedures

Data was obtained from EDHS 2016 which were composed of important variables like: age, educational background, place of residence, frequency of listening radio, women's wealth index, number of children and respondent's current working status with exclusion criteria. 
- $\quad$ Data Analysis Procedures

Epi- Info window version 6.5 statistical programs was used to clean and enter the data into a computer. For further data, exporting and analysis SPSS windows version 23.0 was used. Modern contraceptive use between each predictors and predicted variable was initially performed by bivariate analysis. Each predictors' odds ratios (OR) at $95 \%$ confidence intervals $(\mathrm{Cl})$ and p-values were calculated. Then all statistical significant variables at $p<0.05$ were entered into multivariate analysis using the logistic regression model. Finally, the results were presented in the form of tables, figures, and summary statistics.

\subsection{Operational definition}

Family Planning: - method to regulate the number and spacing of children in a family among none married and marred, through the practice of contraceptive or other method of birth control (23).

Modern contraceptive Methods:-Female sterilization, male sterilization, the pill, the intrauterine device (IUD), injectables, implants, condom and diaphragm/ foam/jelly.

\section{Traditional methods - rhythm (Calendar method), withdrawal and folk.}

- Results

- Socio-demographic characteristics

Ethiopian Demographic and Health Survey (EDHS 2016) data set was examined to assess modern contraceptive use with respect to their demographic, socio-economic and proximate factors. The total number of women covered in this study is 3260 of reproductive age group from 36-49 years. The mean age of women was 41.7 years ( $S D \pm 3.879$ ) among $36-49$ years of users. Of these reproductive age groups women having less than or equal 4 children account $963(29.5 \%)$ while 2297(70.5\%) were had greater 4 children. Only $1268(39 \%)$ women respond as they were currently engaging with work but the rest $61 \%$ of women were not engaging at work. Women resides in rural areas covers $2432(74.6 \%)$ whereas $828(25.4 \%)$ resides in urban centres. Women who listened about Modern contraceptive information via radio accounts $1772(54.4 \%)$ not at all, $918(28.2 \%)$ less than once a week and $570(17.5 \%)$ at least once a week. See table 1

As the graph 1 show; less 554 (17\%) women were utilize modern contraceptive methods in their life time as compared to large number of women $2706(83 \%)$ that did not experience to take any modern contraceptive methods at their reproductive ages. See Graph 1

As we see from table 2, Wealth index is an important factor to utilize modern contraceptive methods in order to minimize unintended pregnancies. Regarding to Women's wealth index about $858(26.3 \%)$ was observed among the richest women followed by $848(26 \%), 550(17 \%), 503(15.5 \%) \& 501(15 \%)$ were the 
poorest, poorer, middle \& and richer women respectively. Among the groups there was a variation of modern contraceptive utilization practice which was 53(6.2\%) in poorest, 93(16.7\%) was in poorer 84 $(16.7 \%)$ was in middle, $100(20.0 \%)$ was in richer, and $224(26.1 \%)$ was in the richest women (see table 2 ).

The graph 2 indicates that Women's educational level had its own contribution on modern contraceptive use practice. Majority of women $2402(73.7 \%)$ were not attending any educational level whereas about $602(18.5 \%)$ women were attending primarily level but only $147(4.5 \%)$ and $109(3.3 \%)$ women reached at their secondary and higher educational levels. Those women who were attending their secondary 55/147(37.4\%) and higher educational levels 41/109(37.6\%) had used more modern contraceptive methods than those women attended their primary 142/602(23.6\%) and those did not attend any educational levels 316/2402(13.1\%).

- $\quad$ Factors associated with contraceptive method utilization

Before preceding data analysis, the necessary assumptions for the application of multiple logistic regressionswas checked by Hosmer and Lemeshow Test through forward LR method. Based on HosmerLemeshow test output at $a=0.05$ we fail to reject the hypothesis that the data fit the model $(p=0.313)$. Therefore, we conclude that the model provides a good fit to the data as $p=0.313(>0.05)$. This indicates that the model was good fit to conduct the data analysis.

From this multivariable binary logistic regression analysis: women's level education, Women's Wealth index, Age, Educational level, and Number of children were significantly associated with use of modern contraceptive methods. The most important factor significantly associated with use of modern contraceptive methods is women's age, for one-year increase in the age of the woman, the log odds of modern contraceptive use decreases by 0.886 or $12 \%$ (AOR; $0.886 \& 95 \% \mathrm{Cl}(0.863,0.910)$. The richest women had 4.120 times more likely to use modern contraceptives than the poorest women did (AOR; $4.120 \& \mathrm{Cl}(2.853,5.949)$. Women who were attending higher education $41(37.6 \%)$ were 3.329 times more likely to utilize modern contraceptive as compared to women not attending any education (AOR; 3.329 \& $95 \% \mathrm{Cl}(2.065,5.368)$. The number of living children a woman had was significantly associated with use of modern contraceptive methods. Women who have more than four children (16\%) were 1.714 times more likely to utilize modern contraceptives than women who have less than equal to four children (AOR; $1.714 \& 95 \% \mathrm{Cl}(1.328,2.212)$. But socio demographic variables like their working behaviour, frequency of radio listening and place of residence did not show any statistically significant difference with modern contraceptive use (see table 2)

\section{Discussion}

Ethiopia has the second largest population in sub-Sahara Africa. Delay and spacing childbearing are important to women's social and economic improvement (6).

In this assessment the prevalence of modern contraceptive method uses among women of age (36-49 years) in Ethiopia is very low (17\%) as compared to the findings revealed in Asia and Latin America 
(57.4\%) (9). This may be due to cultural, educational and economic status difference. Or women living in low income countries may not had an opportunity to learn about the importance of modern contraceptives use or there may be a gaps in women's knowledge how large number of children and repeated abortion can alter the their and family survival.

There is a disparity in modern contraceptive prevalence rates within wealth indexes. The richest women were more likely utilize modern contraceptives than poorest women. This finding is supported by different studies conducted at some countries which were positively associated with the use of modern contraceptives (12). This may be due to that women having earnest wealth index could able to have enough money for transportation, FP service and procedural costs for modern contraceptive method. Or the poorest women may be more engaged with traditional family planning methods due to fear of services cost

Education was the most important variable which was affecting modern contraceptive use in Ethiopia. Women attended their secondary and higher levels of education were more likely to utilize modern contraceptive methods than women not attending any educational levels. This finding is similar with a study conducted across the developing world which revealed that the better educated a woman is, the more likely she is to use contraception (13). This may be due various reasons. For instance; when women became more educated, they may have better understanding about the importance of modern contraceptive use for themselves and their families. Or when women are in schools for their most life's, they may want to delay unintended pregnancies so as to complete their learning process.

Numbers of living children was also a significant predictor for modern contraceptive use in this assessment. Women who have more than 4 children were more likely to use modern contraceptive methods than those women who have less than or equal to 4 children. This result was parallel with a study conducted in Ethiopia in 2011 (15). This may be due to women who have more children may reach their desired number of children or family size and women who wanted to end their desire to have a child were more likely to use modern contraceptive methods than those women who wanted another child.

Women's age had almost a similar effect on modern contraceptive utilization, even if it showed statistically significant association with modern contraceptive use.

Some determinants of modern contraceptive use like: women's residence, current job and frequency of listening modern contraceptive messages with radio did not have a statistically significant association with modern contraceptive use.

\section{Conclusion}

Modern contraceptive use in Ethiopia was low. Socio-demographic factors like Educational status, wealth index, age and number of children were associated with contraceptive utilization. 
Expanding contraceptive services confers substantial benefits on women, their families and society. All stakeholders, including the Ethiopian government and the private sector, should increase their investment in modern contraceptive services.

\section{Limitation}

This study was conducted using EDHS 2016 data. As a result, we did not have complete control of the process and it does not have the ability to show how the data is collected perfectly to meet its specific needs.

\section{Abbreviations}

AOR Adjusted Odds Ratio

CSA Central Statistical Agency

EA Enumeration Areas

EDHS Ethiopian Demographic and Health Survey

FP Family Planning

IUCD Intra Uterine Cupper T Device

MOH Ministry Of Health

PHC Population and Housing Census

SPSS Statistical Package for Social Science

US United State

\section{Declarations}

- Ethics approval and consent to participate

To conduct this study ethical clearance and permission were obtained from Institutional review board committee of Bahir Dar university (but the reference number is not appropriate)

- $\circ$ Consent for publication

Not applicable

- $\quad$ Availability of data and materials

This research data is available at the hand of the corresponding Author. 
Dereje Zena

Email: derejezena@gmail.com

- $\quad$ Competing interests

I declare that I have no competing interests.

- $\quad$ Funding

No funding was given to support this study

- $\quad$ Authors' contributions

The corresponding author (DZ) was involved in the conception, design, drafted the manuscript and data analysis of the study. All authors (DZ, AF \& AA) were involved in analysis and interpretation of data. All authors (DZ, AF \& AA) have been involved in critically revising the article for important intellectual content and have given final approval to the version to be published.

- $\quad$ Acknowledgements

My Deepest thank goes to those Health department higher officials providing EDHs 2016 data for the purpose of this study. I would like to thank Bahir Dar University College of Medicine and Health Science Department of Epidemiology and Biostatistics for providing this opportunity for me.

\section{References}

1. Central Statistical Agency (CSA) [Ethiopia]. 1991. Ethiopia National Fertility and Family Survey 1990-91. Addis Ababa, Ethiopia

2. Whitaker AK, Johnson LM, Harwood B, Chiappetta L, Creinin MD, Gold MA. Adolescent and young adult women's knowledge of and attitudes toward the intrauterine device. Contraception. 2008;78(3):211-7.

3. Sonfield $A$ et al., The Social and Economic Benefits of Women's Ability to Determine Whether and When to Have Children, New York: Guttmacher Institute, 2013

4. Ethiopian Central Statistics Agency. 2011. Ethiopia Demographic and Health Survey 2011.

5. Johns Hopkins Bloomberg School of Public Health (2011) Family Planning: Improving the Lives of Women and their Families around the World.

6. The Global Gag Rule Impact Project. Access Denied: The Impact of the Global GAG Rule in Ethiopia. 2005.

7. Central Statistical Agency (2014) Ethiopia Mini Demographic and Health Survey 2014. Addis Ababa, Ethiopia 
8. JE Darroch. Trends in contraceptive use worldwide. United nations, New york,2015.

9. World Contraceptive Reports 2013, UNDESA

10. Daniels K, Daugherty J and Jones J, Current contraceptive status among women aged 15-44: United States, 2011-2013, National Health Statistics Reports, No. 173.

11. Population Reference Bureau: World population data sheet. 2011

12. Mostafa K, Aynul I: Contraceptive Use: socioeconomic correlates and method choices in rural Bangladesh. Asia Pac J Public Health. 2010, 22 (4): 436-450.

13. Chung $W$ and Das Gupta $M$, The decline of children preference in South Korea: the roles of development and public policy, Population and Development Review, 2007, 33(4):757-783

14. Sonfield $A$ et al., The Social and Economic Benefits of Women's Ability to Determine Whether and When to Have Children, New York: Guttmacher Institute, 2013

15. Ethiopian Central Statistics Agency. 2011. Ethiopia Demographic and Health Survey 2011.

16. International Journal of Education ISSN 1948-5476 2011, Vol. 3, No. 1: E9

17. Ethiopia Mini Demographic and Health Survey 2014. Addis Ababa: Central Statstics Authority; 2014.

18. Central Statistical Agency. Ethiopia and ORC Macro: Ethiopia Demographic and Health Survey (EDHS) 2011. Addis Ababa, Ethiopia and Calverton, Maryland, USA: Central Statistical Agency and ORC Macro; 2012.

19. Gakidou E, Vayena E. Use of modern contraception by the poor is falling behind. PLoS.Med 2007;4:.e31doi: 1371/journal.pmed.0040031pmid: 17284155.

20. (Hosseinpoor AR, Victora CG, Bergen N, Barros AJD, Boerma JT. Towards universal health coverage: The role of within-country wealth-related inequality in 28 countries in sub-Saharan Africa. Bull World Health Org. 2011;89: 881-890. pmid:22271945)

21. Creanga $A A$, Gillespie D, Karklins $S$, Tsui AO. Low use of contraception among poor women in Africa: An equity issue. Bull World Health Org. 2011;89: 258-266.

pmid:21479090

22. https://theodora.com/wfbcurrent/ethiopia/ethiopia_people.html

23. US Dept. of Health, Administration for children and families

\section{Tables}

Table 1: showing Socio demographic characteristics of modern contraceptive use among women of reproductive age from 36-49 years in Ethiopia $(N=3260)$. 


\begin{tabular}{|l|l|l|}
\hline Place of residence & 828 & 25.4 \\
\hline Urban & 2432 & 74.6 \\
\hline Rural & 2402 & 73.7 \\
\hline Educational background & 18.5 \\
\hline No education & 602 & 4.5 \\
\hline Primary & 147 & 3.3 \\
\hline Secondary & 109 & 54.4 \\
\hline Higher & 1772 & 28.2 \\
\hline Frequency of listening to radio & 17.5 \\
\hline Not at all & 918 & 26.0 \\
\hline Less than once a week & 570 & 16.9 \\
\hline At least once a week & 5 & 15.4 \\
\hline Women's wealth index & 848 & 15.4 \\
\hline Poorest & 550 & 26.3 \\
\hline Poorer & 503 & \\
\hline Middle & 501 & 29.5 \\
\hline Richer & 858 & 70.5 \\
\hline Richest & Frequency & Percent (\%) \\
\hline Variable & 963 & 61.1 \\
\hline Number children & 2297 & 38.9 \\
\hline$\leq 4$ & 1992 & \\
\hline$>4$ & 1268 & \\
\hline Respondent currently working & \\
\hline No & \\
\hline Yes &
\end{tabular}

Table 2: showing Socio-Demographic factors associated with modern contraceptive use among women of reproductive age from 36-49 years in Ethiopia $(N=3260)$. 


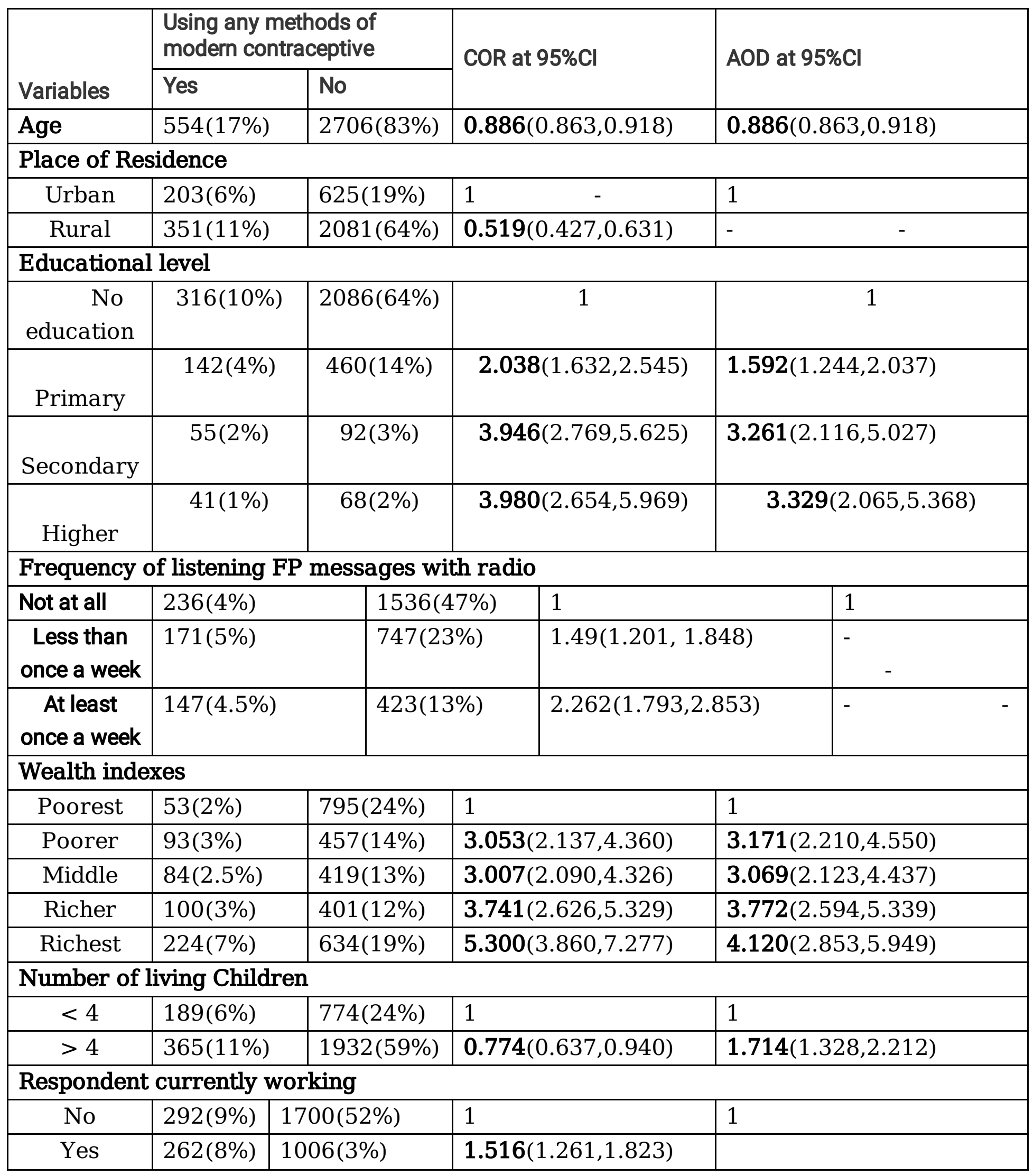




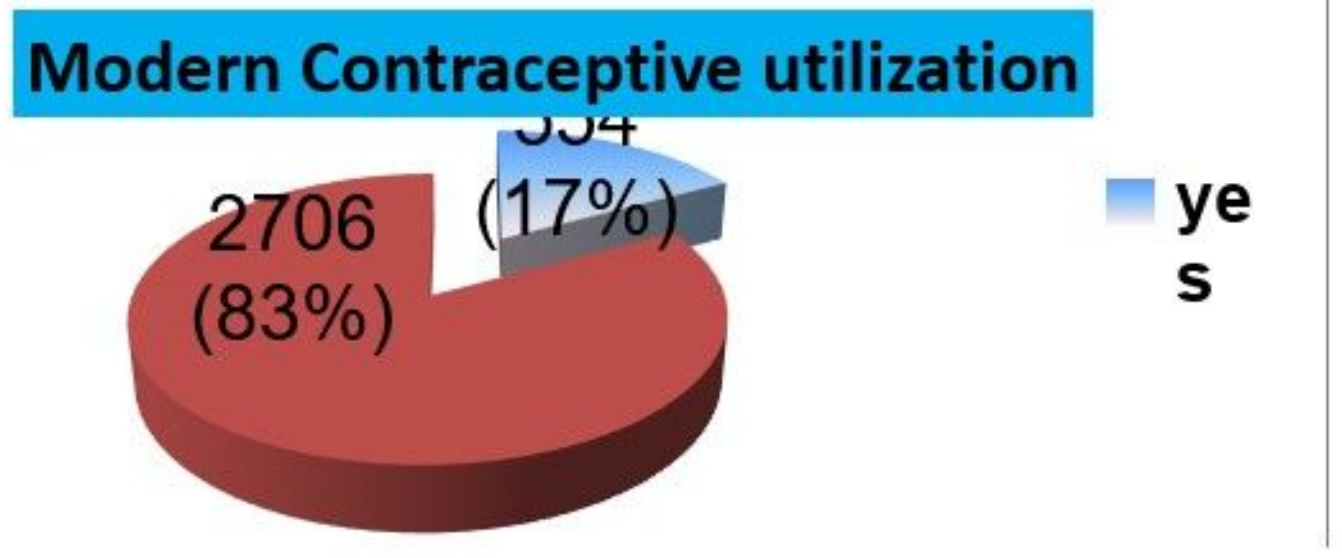

Figure 1

Graph 1: Pie chart showing modern contraceptive use among women of reproductive age from 36-49 years in Ethiopia $(\mathrm{N}=3260)$. 